\title{
PENTINGNYA KEPALA SEKOLAH MENGETAHUI TEKNIK-TEKNIK SUPERVISI DALAM RANGKA MENINGKATKAN KINERGA GURU
}

\author{
Oleh: Fadilla Windryani \\ windriani2408@gmail.com
}

\begin{abstract}
Abstrak
Pentingnya bagi seorang kepala sekolah memastikan bahwa pendidik yang ada di lembaganya memiliki potensi yang bagus dalam melakukan kegiatan pengajawan di kelas. Untuk memastikan bahwa k9nerja pendidika di sekolahnya bagus kepala sekolah juga penting dalam nengetahui teknikteknis supervisi agar dalam emlakukan kegiatan supervisi kepada para pendiidk kepala sekola htidak slah langkah.
\end{abstract}

Kata kunci: teknik-teknik supervisi, meningkatkan kinerja guru.

\section{LATAR BELAKANG}

Pada saat sekarang ini sangat penting bagi seorang guru untuk memastikan bahwa anak didik yang diajarkannya harus berhasil dan sekolah dapat menciptakan output yang terpakai di masyarakat. Untuk itu guru harus mempunyai kompetensi yang mamadai. Tidak hanya guru kepala sekola hjuga penting dalam mengetahui sejauh mana kompetensi yang dimiliki oleh pendidik di lembaganya demi mewujudkan upaya tujuan pendidikan yang ada di sekolah tersebut. Kepala sekolah harus mengetahui bagaiman eknis dan teknik dalam melkaukan kegiatan supervisi terhadap kinerja mengajar guru di dalam kelas

Kepala sekolah sebagai supervisor di sekolah menduduki peran yang penting dalam menentukna terwujud atau tidaknya tujuan pendidika ndi sekolah tersebut. Dimana peran kepala sekolah ialah memastika nbahwa pendidik di sekolah tersebut memenag benar-benar memiliki kemampuan yang memadai dalam melakukan 
kegiatan pengajaran di sekolah. Untuk itu kepala sekola hjuga harus memiliki ilmu mengenai bagaiamna seharusnya proses supervisi dilakuakn kepada pendidik dan bgaimana pula keknik yangtepat dilakukan oleh kepala sekolah dalam melakuakn kegiatan supervisiterhaap guru-guru di sekolah tersebut.

\section{RUMUSAN MASALAH}

1. Konsep dasar supervisi pendidikan

2. Teknik-teknik supervisi pendidikan

3. Peran kepala sekolah dalam supervisi pendidikan di sekolah

\section{TUJUAN PEMBAHASAN}

Berdasarkan rumusan masalah yang telah dirumuskan oleh penulis maka tujuan pembahasan artikel ini adalah untuk mengetahui bagaimana pentingnya peran kepala sekolah dalam upaya melakukan kegiatan supervisi untuk para pendidik di sekolah tersebut. Serta mengetahui bagaimana teknik-teknik yan tepat dihgunakan oleh kepalasekoal hdalm upaya peningkatan kompetensi guru-guru yang mengajar di sekolah tersebut setelah dilakukannya kegiatan supervisi oleh kepala sekolah.

\section{PEMBAHASAN}

1. Konsep dasar supervisi pendidikan

supervisi merupakan bagian dari proses adaministrasi dan manajemen. Kegiatan supervisi melengkapi fungsi-fungsi administrasi yang ada di sekolah sebagai fungsi terakhir yaitu penilaian terhadap semua kegiatan dalam mencapai tujuan pendidikan. Secara simatik supervisi pendidikan adalah pembinaan yang berupa bimbingan yan gdiberikan bimbigna yang diberika noleh supervisor terhadap supervisi dalam lingkup pendidikan. Jika dibawakan dalam lingkup sekolah maka supervisi pendidikan bisa dilakukan 
oleh kepala sekolah terhadap guru-guru yang mengajar di sekolah tempatnya mengajar.

Menurut Sabandi dalam (Sabandi, 2013) supervisi yang dilakukan oleh pengawas diatur dalam Permen Diknas Nomor 12 Tahun 2007 tentang Standar Pengawas Sekolah/Madrasah. Dimensi kompetensi pengawas sekolah/madrasah meliputi: (1) kompetensi kepribadian, (2) kompetensi supervisi manajerial, (3) kompetensi supervisi akademik, (4) kompetensi evaluasi pendidikan, (5) kompetensi penelitian pengembangan, dan (6) kompetensisosial. Berdasarkan Permen Diknas nomor 12 tahun 2007 dan Permen Diknas nomor 13 tahun 2007, bahwa kepala sekolah dan pengawas sekolah/madrasah memiliki tanggung jawab dalam meningkatkan profesionalitas guru.

Supervisi yang dilakuukan oleh kepalasekolah terhadap guru bertujuan untuk meningkatakn kinerja dan profrsionalisme guru dalam kegiatannya memberika npengajaran di kelas. Sebenarnya tujuan akhir dilakukannya supervisi di lingkungan pendidikan ialah untuk mencapai tujuan pendidikan yaitu menciptakan output pendidikan yang siap pakai di kalangan masyarakat pada kehidupan sehari-hari. maka dari itu sangat perlu dipastikan bahwa kompetensi yang dimiliki guru haruslah maksimal agar dapat mencapai tujuan pendidikan tersebut.

Ahmad Sabandi dalam (Sabandi, 2013) mengemukakan bahwa perkembangan supervisi pendidkan berkembang sesuai dengan perkembangan ilmu pengetahuan, teknologi dan sosial ekonomi seta buaya masyarakat.supervisi lebih bergerak dari inspeksi dimana lebih didominasi oleh supervisor berkembang dalam bentuk kolaborasi antara supervisor dan guru dan bertanggungjawab dalam perkembangan pembelajaran serta menumbuhkan budaya belajar pada guru untuk selalau meningkatkan kompetensinya. 
Good carter merumuskan pengertian supervisi pendidikan ialah usaha dari petugas-petugas sekolah dalam memimpin guru-guru dan petugas lainnya dalam memperbaiki pengajaran termasuk menstimulir menyeleksi pertumbuhan jabatan da nperkembangan guru-guru dan merevisi tujuan-tujuan pendidikan, bahan pengajaran dan metode mengajar dan evaluasi pengajaran.

Dari pengertian yang dikemukakan oleh good carterdiatas dapat kia ambil kesimpulan bahwa supervisi tidak hanya dilakukan terhadap guru-guru saja tapi juga terhadap komponen lain yang ada di sekolah. Akan tertapi supervisi lebih cenderung dilakuakn terhadap guru karena guru adalah faktor penting yang menjadi hal yang harus diperhatikan untuk mencapai tujuan pendidka nyan gtelah di sebutkan sebelumnya.

Dari pengertian supervisi diatas dapat ditarik suatu kesimpulan bahwa tujuan supervisi pendidikan ini sebenarnya ialah untuk meningkatkan kinerja guru-gur ataupun komponen lainnya yang ada di sekolah. Tidak hanya meningkatkan kinerja guru yan gda di sekolah tersebut supervisi pendidikan juga bertujuan untuk menciptakan keprofesionalisme seorang guru agar dalam melakukan kegiatan pengajaran di sekolah.

2. Teknik-teknik supervisi pendidikan ada 2 teknik supervisi yang digunakan dalam supervisi di sekolah yaitu supervisi secara individu dan supervisi secara kelompok. Berikut akan dijelaskan lebih rinci mengenai teknik-teknik supervisi:

a. Teknik supervisi secara individu

Ialah suatu teknik supervisi yan gdialkaukan langsung oleh kepala sekolah terhadap seorang guru. Hal ini dinilai efektif akrena guru akan disupervisi langsung oleh kepala sekolah sehingga akan lebih mudah bagai seorang guru menerima apa yangdisampaikan oelh kepal sekolah. Teknis dari supervisi secara individu ini ialah bisa dengan kepala sekolah melakukan observasi di kelas saat guru sedang melakuka nkegiatan pembelajaran. 
Disana lah kepala sekolah mengamati bagaimana guru tersebut dalam mengajar apakah kemampuan guru sudah memadai dan mencapai apa yang diinginkan oleh kepala sekolah ataukah belum. Jika belum maka guru tersebut akan ditindak lanjuti oleh kepala sekolah nantinya. Tindak lanjut ini bisa berupa dari kepala sekolah bicara empat mata dengan guru tersebut. Kemudian jika memang benar-benar tidak bisa maka guru tersebut bisa diberikan pembinaan melalui berbagai-berbagai pelatihan agar kometensi guru tersebut bisa dikembangkan dan dapat diaplikasikan di kelas nantinya.

b. Teknik supervisi secara berkelompok

Berbeda dengan teknik sebelumnya teknik supervisi pendidika nsecara berkelompok ini dilakukan oleh supervisor kepada sekelompok orang yang disupervisi. Dalam supervisi ini guru yang memiliki masalah yang sama dikelompokkan kemudian diberikan bimbingan oleh seorang supervisor yang kompeten sehingga semua guru yang menghadapi masalah yang sama dapat mengetahui dimana kekurangan mereka dan bisa mengevaluasi kekurangan mereka sendiri. Disana mereka diberika nsolusi yang dirasa pas untuk mengatasi permasalahan yangdihadapi oleh par guru tersebut.

3. Peran kepala sekolah dalam supervisi pendidikan di sekolah

Kepala sekolah sebagai supervisor dan menduduki jabatan tertinggi di sekolah sangatlah berperan penting dalam supervisi di sekolah. Salah satu peran kepala sekola hdala msupervisi di sekola hialah memastikan bahwa setiap guru yang memiliki kekurangan dalam hal mengajar mendapatlkan pembinaan yang baik. Sehingga kekurangannya tersebut bisa diatasi dengan pembinaan tersebut. Tujuan utama dari dilakukannya supervisi di sekolah ialah untuk mengetahui sejauh mana kemampuan guru terebut dalam menerapkan pembelajaran yang tebaik di dalam kelas saat keigatan belajar mengajar sedang berlangsug. Untuk itu perankepala sekolah sanatkah 
penting. Akrena kepala sekolah lah guru yang memiliki kekurangan bisa mendapatkan pengetahuan temabahan dan bisa lebih efektiflagi dlam kegiratan mengajar di dalam kelas

\section{KESIMPULAN}

Kepala sekolah selaku pemimpin di sekolah wajib mengetahui keadaan semua staff di sekolah tempat ia memimpin. Termasuk keadaan guru dalam kegiatan belajar mngajar. Salah satu upaya yang bisa dilakukan oleh kepala sekolah dalam meperhatikan keadaan guru adalah dengan melakukan supervisi di lingkungan sekolah. Supervisi bisa dilakukan dengan dua teknik yaitu teknik supervisi secara langsung dan teknik supervisi yang dialukan secara berkelompok. Selain itu ada pula teknik supervisi yang dilakukan secara langsung dan ada pula teknik yang dilakukan secara tidak langsung. Pada dasarnya semua teknik yang ada bertujuan untuk membantu guru dalam mengembangkan kemampuannya dengan baik sehingga kegiatan pembalajaran dapat dilakukan dengan efektif nantinya.

\section{Referensi}

Sabandi, A. (2013). SUPERVISI PENDIDIKAN UNTUK PENGEMBANGAN PROFESIONALITAS GURU BERKELANJUTAN. Pedagogi, Jurnal Ilmiah Ilmu Pendidikan, XIII(2), 1-9. Retrieved from http://ejournal.unp.ac.id/index.php/pedagogi/article/view/4275 